\title{
Article \\ Connecting Climate and Communicable Disease to Penta Helix Using Hierarchical Likelihood Structural Equation Modelling
}

\author{
Rezzy Eko Caraka $1,2,3,4,5, * \mathbb{C}$, Maengseok Noh ${ }^{6, *}$, Rung-Ching Chen ${ }^{3, *}$ (D) Youngjo Lee $^{2}$, Prana Ugiana Gio ${ }^{7}$ \\ and Bens Pardamean ${ }^{5,8}$ \\ 1 Faculty of Economics and Business, Campus UI Depok, Universitas Indonesia, West Java 16426, Indonesia \\ 2 Lab Hierarchical Likelihood, Department of Statistics, College of Natural Science, Seoul National University, \\ Seoul 08826, Korea; youngjo@snu.ac.kr \\ 3 Department of Information Management, College of Informatics, Chaoyang University of Technology, \\ Taichung 41349, Taiwan \\ 4 Medical Research Center, Seoul National University Hospital (SNU-H), Seoul 03080, Korea \\ 5 Bioinformatics and Data Science Research Center, Bina Nusantara University, Jakarta 11480, Indonesia; \\ bpardamean@binus.edu \\ 6 Department of Statistics, Pukyong National University, Nam-gu, Busan 608-737, Korea \\ 7 Department of Mathematics, Universitas Sumatera Utara, Medan 20155, Indonesia; gioprana89@gmail.com \\ 8 Computer Science Department, Bina Nusantara University, Jakarta 11480, Indonesia \\ * Correspondence: rezzyekocaraka@gmail.com or rezzy94@snu.ac.kr (R.E.C.); msnoh@pknu.ac.kr (M.N.); \\ crching@cyut.edu.tw (R.-C.C.)
}

Citation: Caraka, R.E.; Noh, M.; Chen, R.-C.; Lee, Y.; Gio, P.U.; Pardamean, B. Connecting Climate and Communicable Disease to Penta Helix Using Hierarchical Likelihood Structural Equation Modelling. Symmetry 2021, 13, 657. https:// doi.org/10.3390/sym13040657

Academic Editor: Jan Awrejcewicz

Received: 24 February 2021

Accepted: 23 March 2021

Published: 12 April 2021

Publisher's Note: MDPI stays neutral with regard to jurisdictional claims in published maps and institutional affiliations.

Copyright: (C) 2021 by the authors. Licensee MDPI, Basel, Switzerland. This article is an open access article distributed under the terms and conditions of the Creative Commons Attribution (CC BY) license (https:// creativecommons.org/licenses/by/ $4.0 /)$.

\begin{abstract}
Design: Health issues throughout the sustainable development goals have also been integrated into one ultimate goal, which helps to ensure a healthy lifestyle as well as enhances well-being for any and all human beings of all social level. Meanwhile, regarding the clime change, we may take urgent action to its impacts. Purpose: Nowadays, climate change makes it much more difficult to control the pattern of diseases transmitted and sometimes hard to prevent. In line with this, Centres for Disease Control (CDC) Taiwan grouped the spread of disease through its source in the first six main groups. Those are food or waterborne, airborne or droplet, vector-borne, sexually transmitted or blood-borne, contact transmission, and miscellaneous. According to this, academics, government, and the private sector should work together and collaborate to maintain the health issue. This article examines and connects the climate and communicable aspects towards Penta-Helix in Taiwan. Finding: In summary, we have been addressing the knowledge center on the number of private companies throughout the health care sector, the number of healthcare facilities, and the education institutions widely recognized as Penta Helix. In addition, we used hierarchical likelihood structural equation modeling (HSEMs). All the relationship variables among climate, communicable disease, and Penta Helix can be interpreted through the latent variables with GoF 79.24\%.
\end{abstract}

Keywords: climate; communicable disease; hierarchical likelihood; penta-helix; structural equation modelling

\section{Introduction}

The General Assembly of the United Nations (UN) on 25 September 2015 in New York, United States, has officially endorsed the Sustainable Development Agenda or Sustainable Development Goals (SDGs) as a global development agreement [1]. Starting in 2016, the 2015-2030 Sustainable Development Goals (SDGs) officially replace the 2000-2015 Millennium Development Goals [2,3]. SDGs contain a set of transformative goals that are agreed upon and apply to the entire nation without exception.

The health aspects of the community will never be exhausted to be discussed mainly if the focus is on community welfare and justice in getting health facilities and healthy living [4]. SDG point 3 discusses good health and community welfare. The main goals in 2030 [5] or later will be to reduce the maternal mortality ratio, end preventable deaths in 
newborns and infants [6], AIDS [7], tuberculosis [8], malaria and other tropical diseases [9], and hepatitis [10]. Meanwhile, other goals include other infectious diseases, reducing one-third of premature deaths caused by non-communicable diseases, through preventive and treatment measures as well as improving mental health and well-being [11].

Then, the next goals include the strengthening of prevention and treatment of the abuse of dangerous substances, including narcotics abuse and the dangerous use of alcohol, globally reducing half of the death and injury rates due to traffic accidents [12]. However, other aspects include ensuring universal access to sexual and reproductive health services, including planning, information, family education, and integrating reproductive health into national strategies and programs. Besides these goals, others include achieving universal health service coverage, including financial risk protection, access to quality essential health services and access to medicines, vaccines that are safe, effective, quality and affordable, and also by substantially reducing mortality and disease caused by hazardous chemicals [13-17].

All of these targets are very optimistic about being realized and in every country, starting from developed countries and even though developing countries try their best [18]. The process of formulating SDGs cannot be separated from the aspirations and inspiration from the central government to the regional governments. Through city associations and regional governments at the global level, local governments have been very active in contributing to the formulation and endorsement of SDGs and time goes by climate change and human lifestyles [19]. Shifting patterns of disease can be seen from several facts, including that the most significant causes of death and illness are infectious diseases such as respiratory infection, tuberculosis, and diarrhea [20].

Nevertheless, since 2010, non-communicable diseases (NCD) such as stroke, heart, and diabetes (catastrophic diseases) have a higher proportion of health care. This is triggered by changes in people's lifestyle patterns toward unhealthy lifestyles such as lack of physical activity, consuming fewer vegetables and fruit, smoking, alcohol consumption, and others. Sexually transmitted diseases such as HIV and AIDS have increased uncontrollably, especially in some developed countries where people tend to have free sex [21,22].

Health transitions occur because of a demographic and epidemiological transition [23]. Demographic transition is a result of urbanization, industrialization, increased income, education levels, and health technology in the community [24]. It will have an impact on the occurrence of epidemiological transitions [25]. Related to changes in the pattern of death that is due to infection, total fertility, the life expectancy of the population, and increased non-communicable diseases or chronic disease epidemiological transition stems from a complex change in health patterns and patterns of significant diseases causing death. There is a decrease in the prevalence of infectious diseases. In contrast, non-communicable diseases increase [26]. This occurs along with changes in lifestyle, socioeconomic, and increased life expectancy [19], which means an increased risk pattern for degenerative diseases such as heart disease coronary [27], diabetes mellitus [28-30] and hypertension [30,31].

Heart and blood vessel disorders often begin with hypertension or high blood pressure. Besides this, hypertension which is an early vascular disorder [32,33] causes kidney disorders, damage the work of the eye, and causes abnormalities or disruption of the brain, so that it can inhibit the maximum utilization of intelligence capabilities. Hypertension or the so-called silent killer is one of the most influential risk factors as a cause of heart disease (cardiovascular) [34]. Heart disease sufferers now reach more than 800 million people worldwide. Approximately $10-30 \%$ of the adult population in almost all countries experience hypertension, and around $50-60 \%$ of the adult population is the central majority whose health status will be better if blood pressure can be controlled. Specifically, the degenerative diseases are defined as the causes of damage and destruction to the tissues. At the same time, they probably occur during the ageing process, and due to unhealthy lifestyles.

This disease arises because of decreased organ function and affects the elderly. Now, degenerative diseases are increasingly found and not only experienced by those who are 
elderly. As a result of the decline in health status, many young people are also at risk of developing a disease that will cost much money, and can even end in death. They can suffer from changes in lifestyle, including diet and physical activity, and suffer from hypertension, dyslipidemia, obesity, diabetes mellitus, coronary heart disease, gout, kidney, and many more.

The number of sufferers of degenerative diseases has also increased, especially in developed and developing countries, as a result of increasing life expectancy, unhealthy lifestyles, and higher rates of recovery from infectious diseases. Besides this, a collection of lifestyle effects (including stress, the development of the food and beverage industry, air pollution, and environmental factors that have accumulated over many years) have also developed into a source of disease. These factors are often blamed as a cause of high cases of degenerative diseases. Health conditions in Taiwan have undergone significant developments in recent years. This development shows the impact of the expansion of the provision of public health facilities. In addition, discussions with some experts in the field of health will also be done to improve insight so that it can produce a solution that is really appropriate [35]. Nevertheless, there are still new challenges as a result of social and economic change.

Taiwan is currently in the midst of an epidemiological transition where non-communicable diseases are increasing dramatically while infectious diseases are still the leading cause of disease. According to the Taiwan Ministry of Health, the sources of disease in Taiwan can be divided into five types of main source classes, including water borne, airborne or droplet, vector-borne, sexually transmitted or blood borne, and contact transmission.

Meanwhile, the education in Taiwan is one of the best in the World [36] and several universities in Taiwan, including the top 100\% [37,38], and it is necessary to do Penta-Helix to solve health problems in Taiwan. Figure 1 defines the framework of study, which includes dimensions of communicable disease, academia, public and government, and climate, the interaction of each of these dimensions is confirmed using latent values. Higher levels of knowledge clearly allow individuals to better assess the threats posed by climate change and reduce the perceived level of uncertainty related to climate change and the impact of pro-environmental behaviors [39]. The role of education in shaping the character of a generation is extremely important, and the number of colleges and universities generally works on the awareness to allow a comprehensive understanding including the points of the sustainable development goals.

The development power of a country or region needs to be supported by all the elements that exist. It cannot accelerate development, it can only be done by one party. Then, comes the concept of 'Penta helix' development in which elements of government, society or [40,41] disabled, institutions for the youth guidance, welfare foundations, and social welfare services centers can be one of the solutions to educate and empower the surrounding community. Previously, structural equation models (SEMs) could be used for exploring the elements that relate to the performance of city [42], customer [43,44] loyalty [45], an empirical investigation effect of project management capabilities, understanding cryptocurrency adoption [46], social vulnerability index [47], and corporate social responsibility in higher education [48]. In this paper, we use hierarchical likelihood towards SEMs by using software Albatross Analytics and STATCAL are presented in Section $2[49,50]$. The analysis is presented in Section 3. Finally, conclusions are indicated in Section 4. 


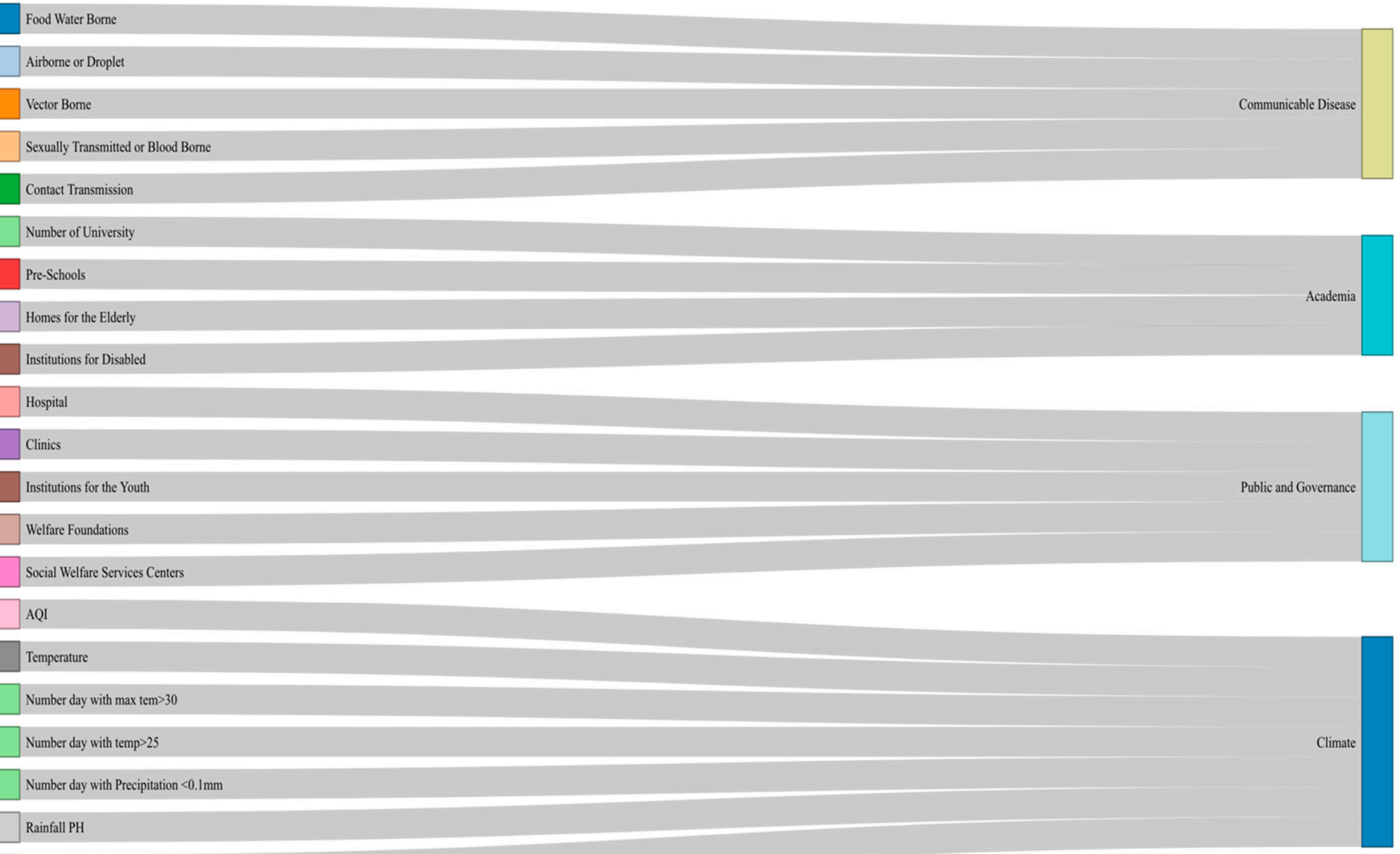

Figure 1. Research Framework.

\section{Hierarchical Structural Equation Models (HSEMs)}

The structural equation model used to test theories or to develop theories (predictive goals). In situations where there is a strong theoretical basis, and theory testing is the main objective of the research, the likelihood approach is more appropriate for reasoning [51]. It is assumed that all variant sizes are useful to explain. Therefore, the approach to estimating latent variables is considered as a linear combination of indicators to avoid the problem of indeterminacy and provide clear definitions of the score component. HSEMs are able to handle two serious problems:

- Inadmissible solution: This happens because variance-based SEMs are not covariance so that the singular matrix problem will never occur.

- Factor indeterminacy: Factor indeterminacy is a condition that causes latent variable scores that cannot be obtained. The sample size in traditional SEMs can be estimated as ten times the number of formative indicators (ignoring reflective indicators) [52-54]. Ten times the amounts of structural paths in the inner model and small sample sizes 30-50 or large samples over 200. In determining the sample size, the HSEM approach states that the strength of the analysis is based on the portion of the model that has the most considerable number of predictors. Minimum recommended ranges are from 30 to 100 cases. HSEMs consist of external relationships (outer models or measurement models) and internal relationships (inner models or structural models) [54]. The relationship is defined as two linear equations, namely the measurement model that unites the relationship of the latent variable with a group of explanatory variables and the structural model that is the relationship among the latent variables [51,52,55].

As in the analysis of structural equation models, the first step in the HSEMs model is the complete specification of the path model consisting of the structural model and the measurement model [56]. Along with structural and measurement models, the path 
model in HSEMs consists of three sets of relationships: First, inner models that specify relationships of latent variables. Second, outer models that specify the relationship among latent variables and their indicators or manifests, and the weight relation where the latent variable score can be calculated. See Appendix A for more details.

\subsection{Inner Model}

This model focuses on the structure model of latent variables, where the latent variables are assumed to have a linear relationship and have a causal relationship [57]. Latent variables can be either exogenous or endogenous latent variables [58]. Endogenous latent variables $\eta$ are latent variables that are predicted by other latent variables [59]. Whereas exogenous latent variable $\xi$ is a latent variable that is never predicted by other variables. Measurement errors in latent variables are denoted by $\zeta$. The inner model can be written as:

$$
\eta_{j}=\beta_{0 j}+\gamma_{0 j}+\sum_{i} \beta_{j i} \xi_{i}+\sum_{i} \gamma_{j i} \eta_{i}+\zeta_{i}
$$

With assumption

$$
\begin{gathered}
E\left(\zeta_{i}\right)=0 \\
E\left(\xi_{i}, \zeta_{i}\right)=0 \\
E\left(\eta_{i}, \xi_{i}\right)=0
\end{gathered}
$$

where:

$i$ : The number of paths from the free latent variable to the non-free latent variable

$j:$ The number of latent variables

$\eta_{j}:$ Latent variable $j$-th

$\eta_{i}$ : Latent variable $i$-th

$\beta_{j i}$ : Coefficient path of the $i$-th exogenous latent variable to the $j$-th endogenous latent variable

$\gamma_{j i}$ : Coefficient of the $i$-th endogenous latent variable to the $j$-th endogenous latent variable $\beta_{0 j}:$ Intercept

$\zeta_{i}:$ Inner residual

\subsection{Outer Model}

To build relationships all of the indicators with their latent variables, outer model refers to the measurement model. The way to build relation indicators and latent variables can use the reflective relationships, formative relationships, and multi-effect indicators for multiple causes (MIMIC) [51]. This model also defines how each block of indicators relates to the latent variable with the following equation:

$$
\begin{aligned}
& x=\bigwedge_{x} \xi+\varepsilon_{x} \\
& y=\bigwedge_{y} \eta+\varepsilon_{y}
\end{aligned}
$$

$x$ and $y$ are an indicator or manifest variable for exogenous latent variables and endogenous latent variables $\xi$ and $\eta$, while $\Lambda_{x}$ and $\Lambda_{y}$ are a loading matrix that describes a simple regression coefficient that links latent variables with indicators. Residuals measured by $\varepsilon_{x}$ and $\varepsilon_{y}$ can be interpreted as a measurement error or noise. Additionally, $\delta_{\xi}$ and $\delta_{\eta}$ are the residual regression. Blocks with formative indicators can be written with the following equation:

$$
\begin{aligned}
& \xi=\prod \xi_{x}+\delta_{\xi} \\
& \eta=\prod \eta_{y}+\delta_{\eta}
\end{aligned}
$$




\subsection{Reflective Relations}

In the reflective relationship in Figure 2, the indicator is a reflection or manifestation of the latent variable, the indicator $X_{i j}$ is assumed to be a linear function of the latent variable $\xi_{j}$.

$$
X_{i j}=\lambda_{0 j k}+\lambda_{j k} \xi_{j}+\varepsilon_{j k}
$$

$\lambda_{j k}$ is the loading coefficient and $\varepsilon_{j k}$ is residual. With assumption $E\left(\varepsilon_{j k}\right)=E\left(\xi_{j}, \varepsilon_{j k}\right)$ which means that the residual has zero mean and does not correlate with the indicator, thus:

$$
E\left(X_{i j} \mid \xi_{j}\right)=\lambda_{0 j k}+\lambda_{j k} \xi_{j}
$$

$j$ is the number of latent variables and $i$ is the number of indicators.

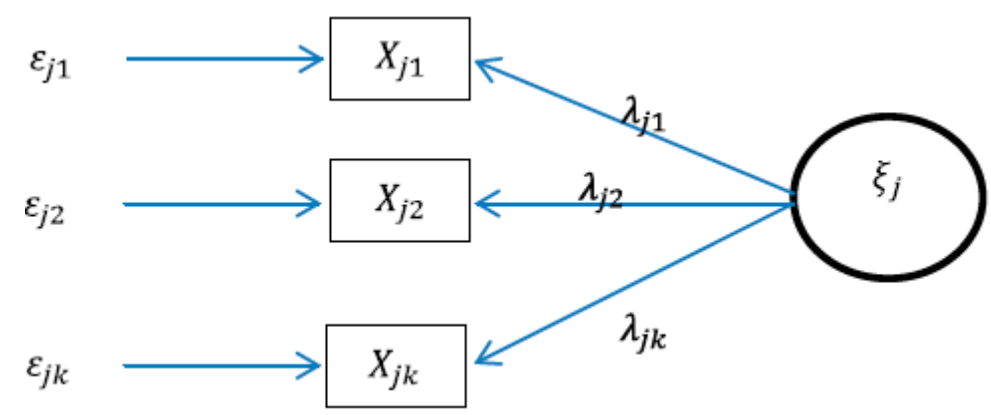

Figure 2. Path for Reflective Relations.

\subsection{Formative Relations}

In the form of formative relationships in Figure 3 the changes in the construct of latent variables are caused by changes in indicators. The latent variable $\xi_{j}$ is assumed to be a linear function of the indicator $X_{j k}$.

$$
\xi_{j}=\pi_{o j}+\sum \pi_{j k} X_{j k}+\delta_{i}
$$

With assumption:

$$
\begin{gathered}
E\left(\delta_{i}\right)=E\left(\xi_{j} \delta_{i}\right)=0 \\
E\left(\xi_{j} \mid X_{j k}\right)=\pi_{o j}+\sum \pi_{j k} X_{j k}
\end{gathered}
$$

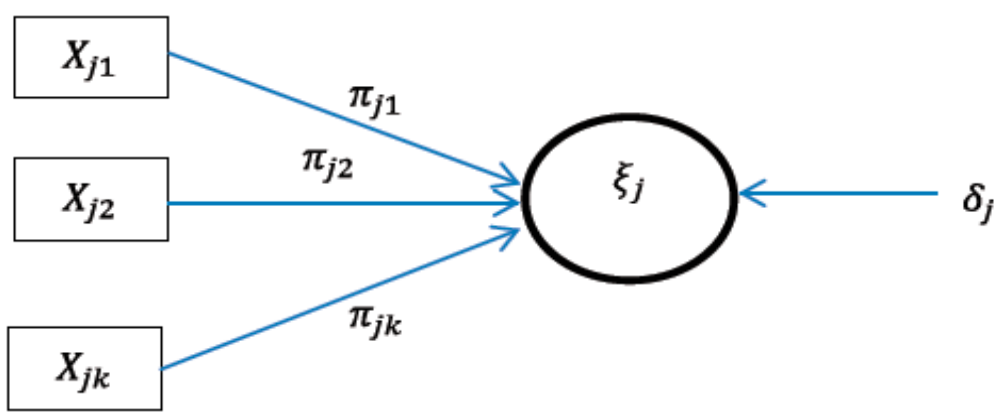

Figure 3. Path for Formative Relations.

SEMs have a function to model the relationship of latent variables with indicators and to model relationships among the latent variables based on pre-existing theories. There are two types of models that are divided into measurement models and structural models. In line with this, SEMs explain the relationship of the latent variables and the measurement indicators carried out through factor analysis, where each latent variable is modelled as a measurement indicator factor. However, SEMs have two types of errors, measurement 
model errors and structural model errors. SEMs cannot predict correctly, so errors in the model might occur. The first is the measurement error. The error measurement is the value or size of the error due to measuring indicators that cannot measure latent variables correctly. Besides this is the parameter estimation for HSEMs obtained through iteration processes. The first iteration produces the path estimation that is used to produce a latent variable score on the indicator. The second iteration produces a path estimate that reflects the contribution of variations in changes in exogenous latent variables to endogenous variables. In the first stage, the estimation in the measurement model is generated from the weight estimation $\lambda_{j h}$ on the reflective indicator model. $h$ Shows many indicators contained in exogenous latent variables $j h=1,2, \ldots p$, whereas $j$ is the exogenous latent variable, $j=1,2, \ldots q$. The reflective indicator model is a model in which the direction of causality relates from the latent variable to the indicator. This is in line with endogenous variables with reflective indicators such as steps to obtain equations using the likelihood.

$$
\begin{aligned}
& \delta_{j h}=x_{j h}-\lambda_{j h} \xi_{j} \\
& \sum_{j=1}^{q} \delta_{j h}^{2}=\sum_{j=1}^{q}\left(x_{j h}-\lambda_{j h} \xi_{j}\right)^{2} \\
& \frac{\partial \sum_{j=1}^{q} \delta_{j h}^{2}}{\partial x_{j h}}=0 \\
& 2 \sum_{j=1}^{q}\left(x_{j h}-\lambda_{j h} \xi_{j}\right)\left(-\xi_{j}\right)=0 \\
& \sum_{j=1}^{q}\left(-x_{j h} \xi_{j}\right)\left(\lambda_{j h}-\xi_{j}^{2}\right)=0 \\
& \lambda_{j h} \sum_{j=1}^{q}\left(\xi_{j}^{2}\right)=\sum_{j=1}^{q}\left(\lambda_{j h} \xi_{j}\right) \\
& \hat{\lambda}_{j h}=\frac{\sum_{j=1}^{q}\left(\lambda_{j h} \xi_{j}\right)}{\sum_{j=1}^{q}\left(\xi_{j}^{2}\right)} \\
& \hat{\lambda}_{j h}=E\left[\frac{\sum_{j=1}^{q}\left(\lambda_{j h} \xi_{j}\right)}{\sum_{j=1}^{q}\left(\xi_{j}^{2}\right)}\right] \\
& y_{j h}=\lambda_{j h} \eta_{j}+\varepsilon_{j h} \\
& \sum_{j=1}^{q} \varepsilon_{j h}^{2}=\sum_{j=1}^{q}\left(y_{j h}-\lambda_{j h} \eta_{j}\right)^{2} \\
& \frac{\partial \sum_{j=1}^{q} \varepsilon_{j h}^{2}}{\partial \lambda_{j h}}=0 \\
& 2 \sum_{j=1}^{q}\left(y_{j h}-\lambda_{j h} \eta_{j}\right)\left(-\eta_{j}\right)=0 \\
& \sum_{j=1}^{q}\left(-y_{j h} \eta_{j}\right)+\left(\lambda_{j h} \eta_{j}^{2}\right)=0 \\
& \lambda_{j h} \sum_{j=1}^{q}\left(\eta_{j}^{2}\right)=\sum_{j=1}^{q}\left(y_{j h} \eta_{j}\right) \\
& \hat{\lambda}_{j h}=\frac{\sum_{j=1}^{q}\left(y_{j h} \eta_{j}\right)}{\sum_{j=1}^{q}\left(\eta_{j}^{2}\right)}
\end{aligned}
$$

Hence, the equation can be written as follows:

$$
\eta_{j}=\beta_{j h} \eta_{j}+\gamma_{j h} \xi_{h}+\zeta_{j h}
$$


The equation will be estimated at the coefficient $\gamma$ use least square against $\xi_{h}$ so it will be obtained.

$$
\hat{\gamma}_{j h}=\left(\left(\xi_{h}\right)^{\prime} \xi_{h}\right)^{-1}\left(\xi_{h}\right)^{2} \eta_{j}
$$

Then, the coefficient $\beta$ will be derived against $\beta_{j h}$.

$$
\begin{gathered}
\frac{\partial\left(\zeta_{j h}\right)^{\prime}}{\partial \beta_{j h}}=0 \\
-2\left(\eta_{j}\right)^{\prime} \eta_{j}+2\left(\hat{\beta}_{j h}\right)^{\prime}\left(\eta_{j}\right)^{\prime} \eta_{j}=0 \\
\hat{\beta}_{j h}=\left(\left(\eta_{j}\right)^{\prime} \eta_{j}\right)^{-1}\left(\eta_{j}\right)^{\prime} \eta_{j}
\end{gathered}
$$

\section{Datasets and Results}

In this study, there are seven latent variables, namely climate, social, food water borne, airborne or droplet, vector-borne, sexually transmitted or blood borne, and contact transmission. Climate latent variable consists of 7 indicators, and social latent variable consists of 11 indicators. Moreover, food water borne latent variable consists of 12 indicators, airborne or droplet latent variable consists of 16 indicators, and vector-borne latent variable consists of 5 indicators. Moreover, sexually transmitted latent variable consists of 5 indicators of 7 indicators and latent variables. There are also 8 types of contact transmission. In testing, the outer model tests the relationship of each latent variable to its indicators. All the datasets provided by the Environmental Protection Administration (EPA) Taiwan are acknowledged.

\subsection{Synergy of Penta-Helix in Health Issues}

Health is a key factor which could be used as one of the parameters for the wellbeing of urban communities. In fact, individuals always have the same chances to get health care facilities. Whenever the underprivileged is needed, that is where the role of the government is deemed necessary. National health insurance in Taiwan is one of the health insurance coverage provided by the government towards its residents throughout the form of a medical assistance. First, the synergy of academicians, local businesses, and local governments is considered capable of quickly resolving problems and producing policies that can be implemented [60,61] This collaboration is called the Triple Helix [62] In the framework of implementing research and innovation strategies, full support from all parties is needed to bring research results into innovations which are then developed by new businesses or assisting the health industry and other national industries in increasing competitiveness. Collaboration industry, small pharmaceutical companies, and patient organizations can provide solutions to rare diseases [63]. Then, innovation is not carried out individually, but must be performed through synergy among all national stakeholders, including academics, business, government, and society which is commonly called Penta Helix. Figure 4 shows all indicators on social latent variables are positively correlated with social latent variables. The most reliable indicators in terms of their correlation to social latent variables are Number of University, Social Welfare Services Center, and Institutions for the Disabled in Taiwan, so, in other words, many universities, social welfare by being able to reduce the spread of disease. It can also be said that the presence of this facility can provide early education to the public to care about the health and also education on types of diseases.

Figure 5 explains that, in general, pharmaceutical, medical-based companies are located in the Taipei area, New Taipei City, Hsinchu, Tainan, Zhubei, and Taichung. The focus area of the company has been to provide health products in Taiwan so that it can be assumed that Taiwan can independently provide excellent service to improve people's welfare, so that it might well participate actively through the Penta Helix collaboration in Taiwan. At this stage, we performed the analysis on the impact of social latent consisting of Number of Clinic (CLIN), Hospital (HOSP), Population Density (POPDEN), Number of University (NUMUNI), Services Centres (SERCENT), Social Welfare (SOCWEL), Welfare 
Foundation (WELFUND), Institutions of Youth Guidance (INSGUI), Institutions for the Disabled (INSDIS), Homes for the Elderly (HOMELD), and Pre-Schools (PRESC).

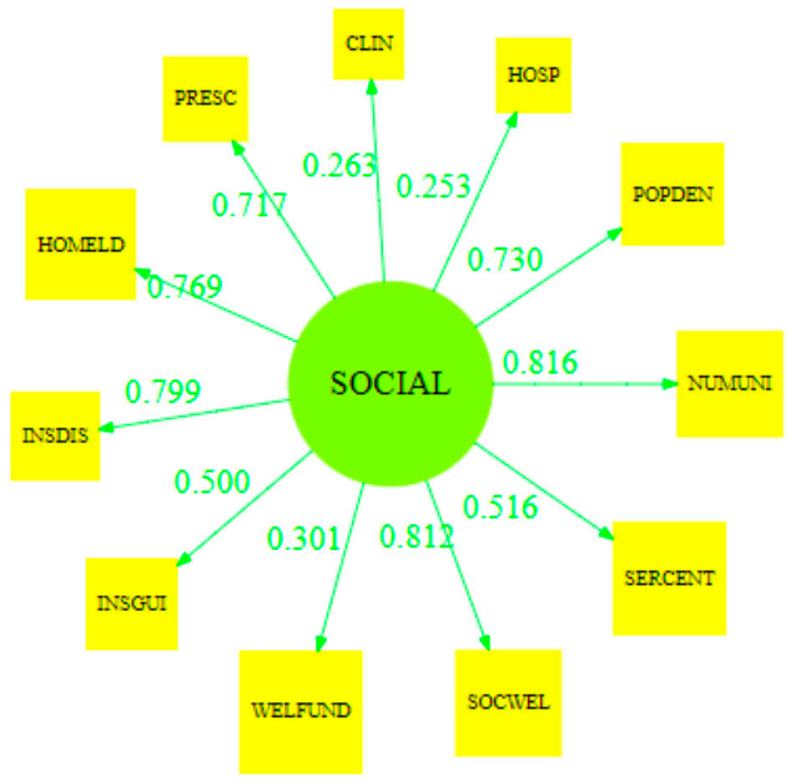

Figure 4. The Loading Value for Each Indicator of Social Latent Variables.
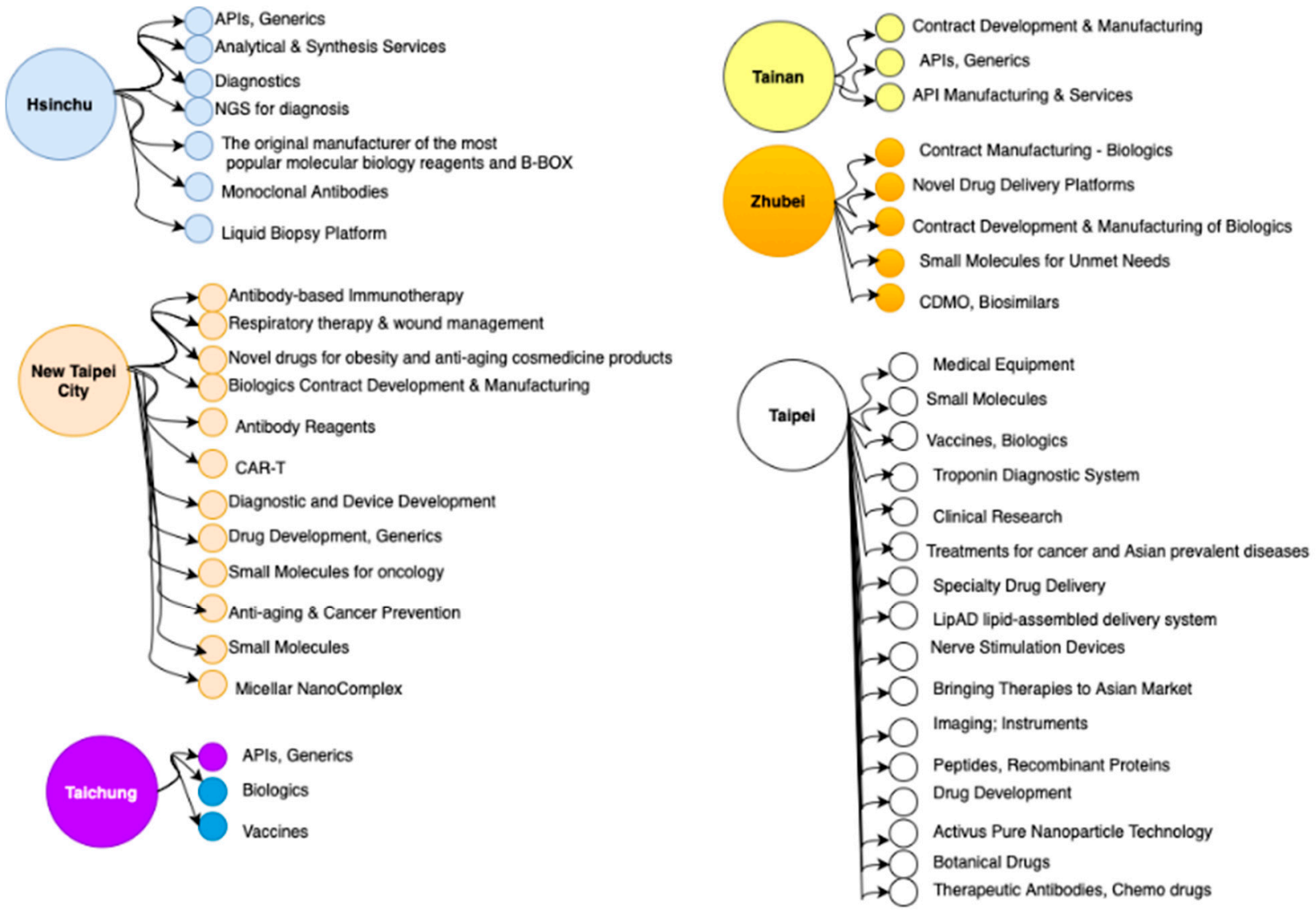

Figure 5. Focus Company in Taiwan. 


\subsection{Communicable Disease}

The Centers for Disease Control, R.O.C. (Taiwan) grouped the spread of disease through its source in the first six groups, namely: food or waterborne, airborne or droplet, vector-borne, sexually transmitted or blood-borne, contact transmission, and miscellaneous. Broadly speaking, for communicable disease, a relationship will be made between each latent spread of the disease based on the source. One of the values that can be used to test outer models is the loading value. The loading value states the correlation among the latent variable and the indicator. The higher the loading value, the closer the correlation is among the latent variable and the indicator. Figure 6 shows that all indicators of the Food Water Borne latent variable are positively correlated to the Food Water Borne latent variable. It is known that the three most reliable indicators in terms of their correlation to latent variables of Food Water Borne are Amoebiasis, Listeriosis, and Entovirus. In other words, among the three types of diseases, food waterborne has the most significant impact in Taiwan compared to other types of diseases that enter into food waterborne.

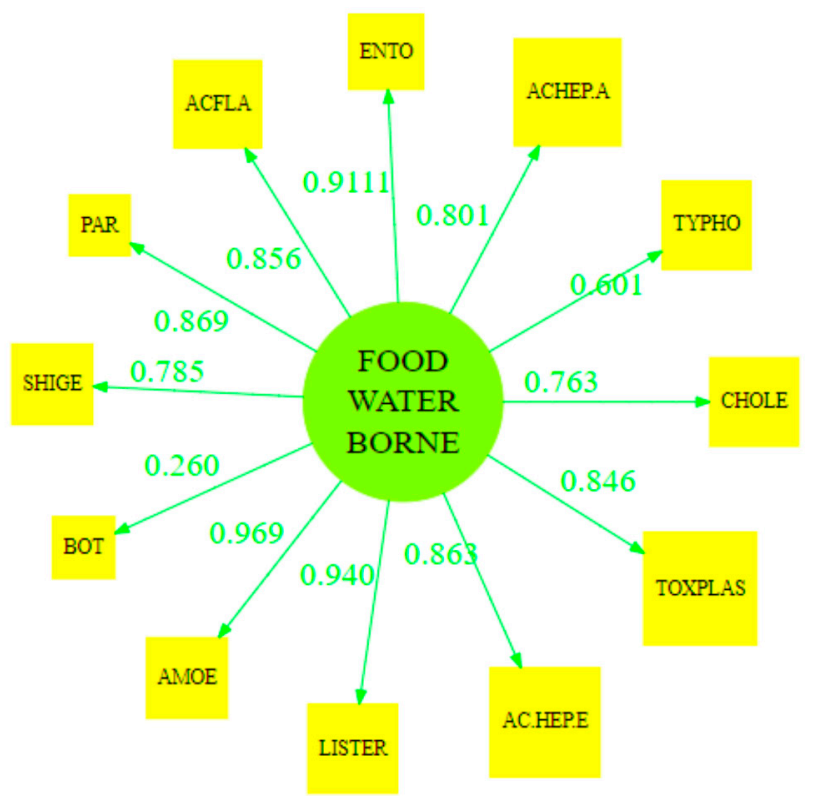

Figure 6. The Loading Value for Each Indicator of the Latent Food Water Borne Variables.

Amebiasis is a parasitic infection of Entamoebae histolytica or E. histolytica in the intestine. Amebiasis often occurs in tropical countries and developing countries that have inadequate sanitation systems. Then, Listeriosis is a dangerous infectious disease that arises from eating food contaminated with bacteria. The bacteria that cause Listeriosis usually live-in undercooked meat and dairy products. Furthermore, the enterovirus enters the human body through the digestive tract, multiplying in the mouth of the throat. After entering the mouth, the virus will multiply in the digestive tract and respiratory tract. After a virus occurs in the blood circulation, the infection will spread to tissues and several organs. Then, it very often found in the patient's stool.

Figure 7 shows that all indicators of the Airborne or Droplet latent variable are positively correlated to the Airborne or Droplet latent variable. The three most significant indicators in terms of their correlation with Airborne or Droplet latent variables are Invasive Pneumococcal, Severe Complicated Influenza, and Legionellosis. 


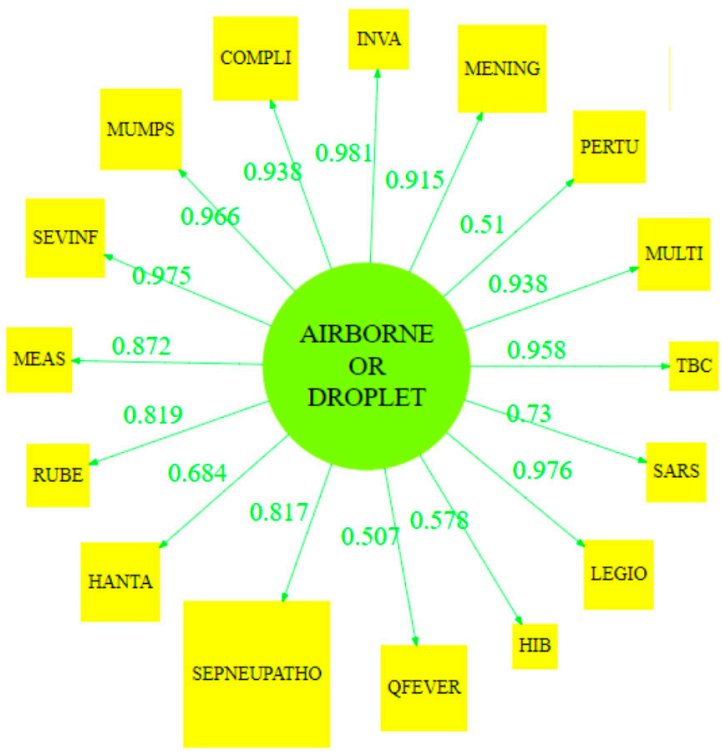

Figure 7. The Loading Value for Each Indicator of the Latent Airborne or Droplet.

Figure 8 shows that all indicators on Vector-Borne latent variables are positively correlated with Vector-Borne latent variables. The most reliable indicators in terms of their correlation to Vector Borne latent variables are Japanese Encephalitis, Malaria, and Zika.

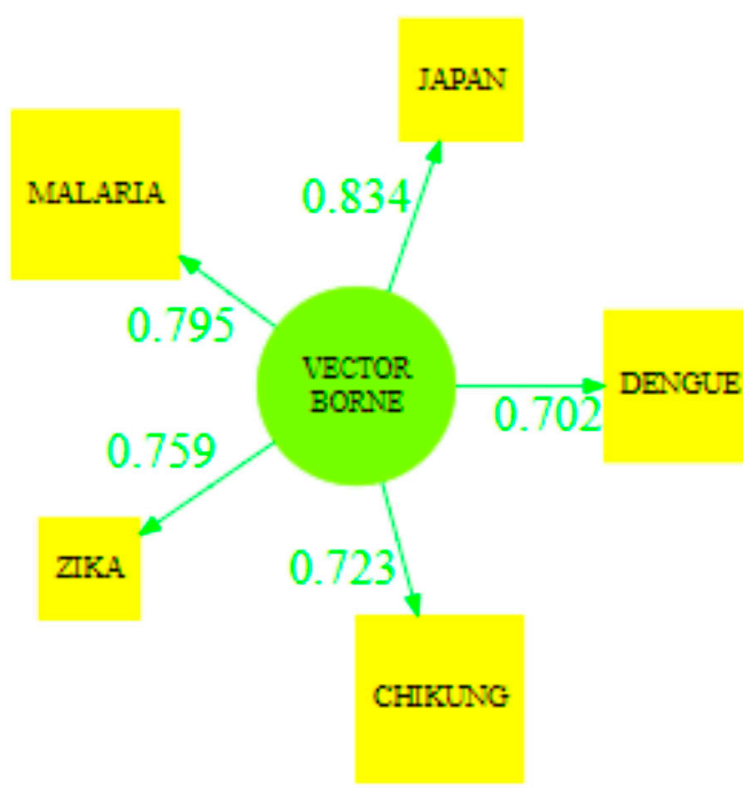

Figure 8. The Loading Value for Each Indicator of the Latent Vector Borne.

Figure 9 shows that all indicators on the latent variable Sexually Transmitted or Blood Borne are positively correlated to the latent variable Sexually Transmitted or Blood Borne. The most reliable indicators in terms of their correlation with latent variables Sexually Transmitted or Blood Borne are HIV, Acute Hepatitis C, and Syphilis. 


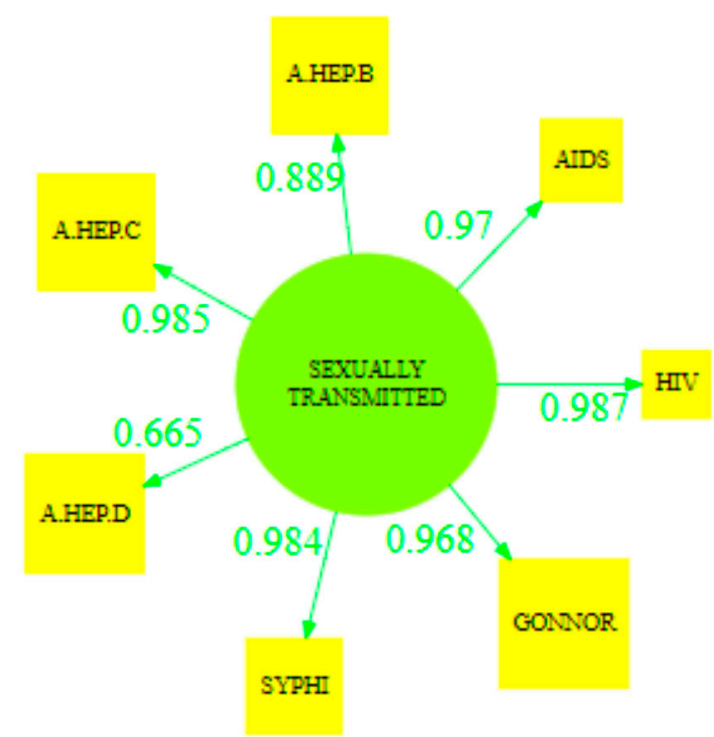

Figure 9. The Loading Value for Each Indicator of the Latent Sexually Transmitted or Blood Borne.

All indicators on the contact transmission latent variable in Figure 10 are positively correlated with the Contact Transmission latent variable. The most reliable indicators in terms of their correlation with the contact transmission variable are Hansen's, Tetanus, and Acute Viral Hepatitis.

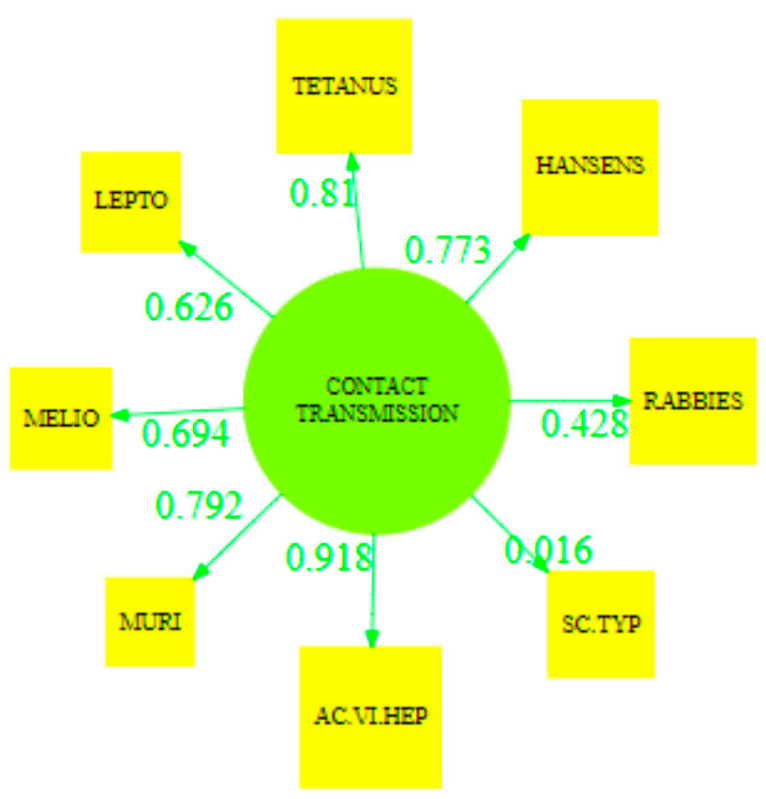

Figure 10. The Loading Value for Each Indicator of the Latent Contact Transmission.

\subsection{Communicable Disease against Climate}

The latent variable Climate in Figure 11 is positively correlated to the latent variable Climate, except for the Number day Precipitation indicator $<0.1 \mathrm{~mm}$ (NDPREC) negatively correlated to the latent variable climate, with a loading value of -0.637 . The 3 strongest indicators in terms of correlation to latent variables are Number day with max tem $>30$ (NUMAXTEM) 0.875, Number Day Temp > 25 (NDTEMP) 0.878, and Rainfall PH (RAIN) 0.683 . 


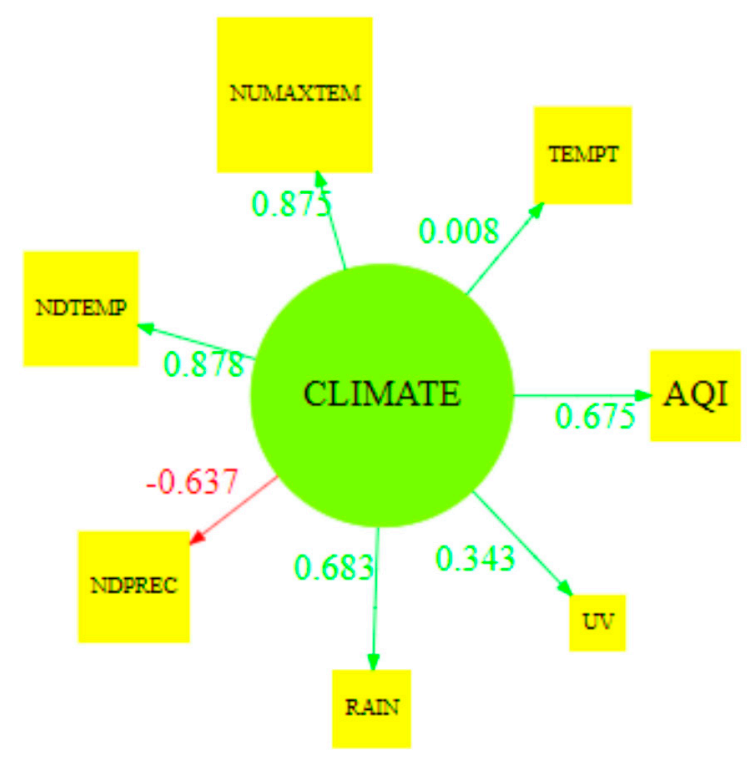

Figure 11. The Loading Value for Each Indicator of the Climate.

The issue of global warming may be a problem that is considered a cliché by some people. Maybe even most of us will not be surprised and panicked about the possibility of a great danger that is ready to surround us, ranging from melting ice, animal extinction, and the emergence of new diseases, followed by a decrease in our body's ability to deal with it due to weather changes [64]. Information regarding the source of virus infection is not yet clear.

However, the possibility of worsening the spread of the virus suspected by the influence of the season [65] needs to be discussed in more detail. In line with this, in cold regions, the spread of the flu becomes very fast due to cold weather and poor air ventilation [66]. Logically, warm weather should be able to inhibit the rate of spread of the virus [67]. Unfortunately, this is not the case. Recent studies do not support the logic above. The big reveal, experts believe that climate change is a boon that actually worsens the disease outbreak. Climate change has influenced the way viruses, such as influenza and even HIV, develop and expanded. This has also been proven that some categories of influenza which can only be infected in the cold season could really remain alive in warm season. There are several types of viruses found in Asia during the summer. These viruses are carried by birds who are immigrating. However, this is not entirely the fault of the birds. Climate change has disrupted their immigration routes. This changing immigration route allows birds to interact with other bird species. This interaction which then spawned is not a new bird species, but a new type of influenza.

These birds eventually transmit and carry these new viruses throughout the world. The influence of weather in various places then causes varying degrees of infection. For experts, until now, predicting the flu is still a complicated thing, given that there are many factors that are related to each other. Even though we know for sure, how will we know when the new disease spread and turns into a pandemic? What has happened maybe a mirror of human powerlessness in dealing with the various obstacles caused by human actions.

In other cases, changes in temperature and humidity as patterns related to climate change will have a further impact on health by changing the ecology of various vectortransmitted diseases such as malaria, dengue, chikungunya, Japanese encephalitis, Kala Azar, and Filariasis. The effects of climate change can also be distinguished of direct and indirect changes when some effects can be easily seen such as increased deaths due to increased frequency and severity of heat waves while others depend on factors such as the distribution of vector populations or other sources of disease. In other words, other effects that are very varied and not obvious to health can come from expulsion or population 
migration. Temperature can affect the distribution of vectors and the effectiveness of pathogens through vectors. For example, mosquitoes can live in low temperatures, but the metabolism decreases and even stops when the temperature drops to the limit of about 10 degrees Celsius.

Then, low humidity can negatively affect mosquito survival and can reduce the proportion of the vector population. It is even clearer that low humidity causes more foraging vectors to overcome the dehydration that occurs. An increase in high temperature and low humidity causes the vector to produce offspring more than double the low temperature with high humidity. Rainfall also needs to be considered, because various mechanisms that are possible to occur by changing rainfall are an increase in standing water that can become a vector breeding area. Low rainfall can also increase breeding sites through slow river flows, and increased rainfall can increase vegetation. The number of rainy days also affects the vector's life cycle and virus replication, because many rainy days are generally suitable for mosquito. Another factor that is likely to influence is the wind speed, because the wind will indirectly affect water evaporation and air temperature confection. In the situation of calm air, the body temperature of mosquitoes may have several fractions one degree higher than the ambient temperature; if there are good wind evaporation and convection, then the mosquito's body temperature drops several fractions one degree lower than the ambient temperature. In short, climate change is related to pathogens, hosts, and the environment as it is known that on the host, the climate can influence behavior conditions and then has a susceptibility to changes in exposure or contact level. When genes provide a mechanism, host immunization or disease resistance is also influenced by the environment. The effects of climate change occur at a rate faster than the host's ability to adapt. Human activities and behavior significantly affect the transmission of other viruses.

\subsection{Model Construction}

To begin, Dillon-Goldstein's rho value is also one of the values in the outer model testing. Dillon-Goldstein's rho value is used to test unidimensionality. Dillon-Goldstein's rho value $>0.7$ is seen as an indicator variable as unidimensional. Nevertheless, DillonGoldstein's rho $0.6-0.7$ can be accepted in exploratory research. Long story short, Table 1 presents Dillon-Goldstein's rho values.

Table 1. Testing the Outer Model based on Dillon-Goldstein's rho.

\begin{tabular}{cc}
\hline Latent Variable & Dillon-Goldstein's rho \\
\hline Climate & 0.640 \\
Social & 0.864 \\
Food Water Borne & 0.957 \\
Airborne or Droplet & 0.975 \\
Vector Borne & 0.886 \\
Sexually Transmitted or Blood Borne & 0.977 \\
Contact Transmission & 0.862 \\
\hline
\end{tabular}

Table 1 shows all Dillon-Goldstein's rho values are $>0.6$, which means that each latent variable has good unidimensionality. After testing the outer model (measurement model), then there further testing the inner model (structural model) was performed. In testing the inner model, an analysis of the relationship among latent variables, Climate, Social, Food Water Borne, Airborne or Droplet, Vector-Borne, Sexually Transmitted or Blood Borne, and Contact Transmission was performed. Figure 12 shows the correlation values of latent variables. The most reliable Communicable Disease indicators in terms of their correlation to Social are Food Water Borne with a correlation value of 0.890 , Vector-Borne with a correlation value of 0.860 , and Contact Transmission with a correlation value of 0.849 . In contrast, the 3 most reliable indicators of communicable disease in terms of its correlation 
to climate are contact transmission with a correlation value of 0.702 , Vector-Borne with a correlation value of 0.693 , and Food Water Borne with a correlation value of 0.566 .

The three indicators most closely related to communicable disease are airborne or droplets (ABDROPLET) with a correlation value of 0.985 , Contact Transmission (CTRANS) with a correlation value of 0.976 , and Food Water Borne (FWBORNE) with a correlation value of 0.975 . Communicable disease and social correlate positively, with a correlation value of 0.885 . Communicable disease and climate correlate positively, with a correlation value of 0.606 . Social and Climate are positively correlated, with a correlation value of 0.754. Overall, Communicable Disease, Social and Climate are positively correlated. At the same time, we performed the goodness of fit $(\mathrm{GoF})$ to test the suitability of our model. GoF index is a pseudo-goodness of fit measure that accounts for the model quality at both the measurement and the structural models. GoF can be used as a global criterion that helps us to evaluate the performance of the model in both the inner and the outer models. Basically, GoF assesses the overall prediction performance of the model. GoF is calculated as the geometric mean of the average communality and the average $R^{2}$ value GoF $=\sqrt{\mu_{\lambda^{2}} * \mu_{R^{2}}}$ and it obtained 0.7924 or $79.24 \%$.

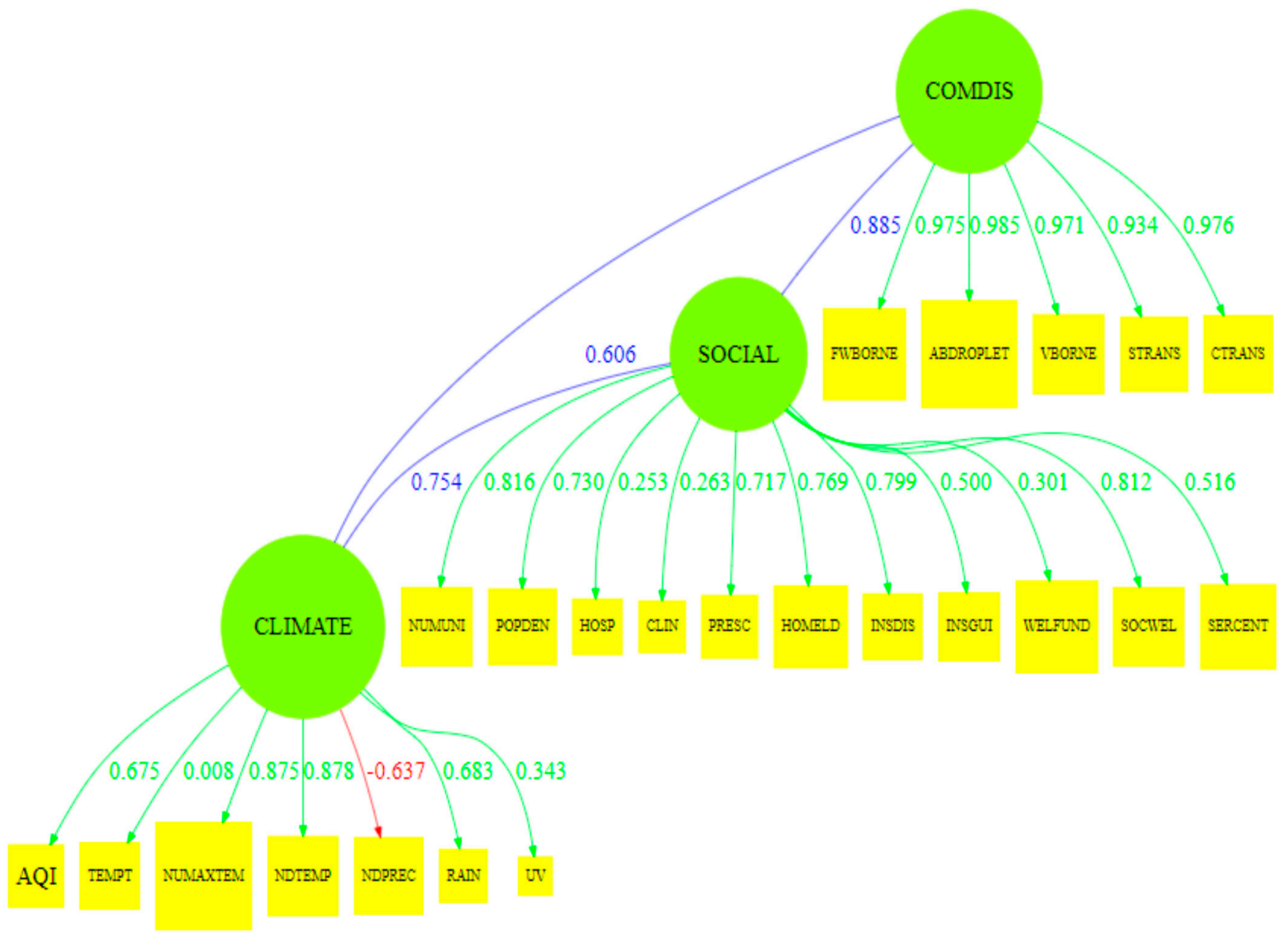

Figure 12. Communicable Disease, Social, and Climate.

\section{Conclusions}

In a nutshell, we present the relation of communicable disease, social, and climate towards Penta Helix. The relationship with each variable is high, such as climate against social is 0.754 , social and communicable disease is 0.885 , and communicable disease against climate is 0.606 , respectively. The authority of the regional government are divided into 
compulsory and optional affairs. Obligatory affairs are government affairs that must be carried out by provincial and district/city regional governments, relating to essential services, for example, education, health, environment, and others. It can be understood that health services are included in the mandatory affairs that must be carried out by the regional government in order to improve the welfare of the community in the health sector in their area. An important feature that distinguishes local authorities from private sector organizations is that the public is not only a customer, but also a citizen. If they are respected as customers, they are also respected as citizens. There is a dual responsibility for local authorities in providing services to the community. To overcome health problems, the role of the regional government in question can be an effective weapon in dealing with political pressure by accommodating and articulating local interests, becoming a media for political education for people who feel the implementation of government functions directly. Because of its proximity to the location, the provision of services can take place more efficiently. Planning can be better, because it knows more about its local conditions, with the use of more efficient local personnel as well. Government officials have a better responsibility, because relations with the public are closer. Local government can be an effective medium of communicable aspects among the centre and local communities related to central government programs in the regions. In order to provide quality services, of course, both qualities must be met. Developing countries generally cannot meet both of these qualities; so, public services are less satisfying. For instance, the substantialquality public services include the services with proper management and emphasizing the regulation of public services. Moreover, there is the Efficiency aspect, emphasizing the provision of better services with available resources. The Economical aspect involves emphasizing the provision of services that are as cheap as possible and accessible to the public (service users).

Additionally, there is the Social justice aspect, emphasizing equal rights in government services; Responsiveness is more towards the needs of citizens than the needs of public organizations. By involving stakeholders in better planning, implementation, and monitoring of the rebuilding process, including local governments, local communities, experts and academics, the media, and the private sector, known as Penta Helix, can be more effective in solving problems, especially in the health sector. The Penta Helix concept is also considered to be able to reduce the tendency of people to be too dependent on the government in dealing with problems around them. Controlling the infectious diseases caused by mosquitoes and other vectors needs to be adequately handled, given the very significant relationship to climate. Future research should be performed in multilevel modelling through, generalized linear latent mixed models (GLMMMs) and generalized linear latent variable models (GLLVMs) [68-71].

A frequentist alternative approach is proposed by Lee and Nelder in 1996 [72], who termed it as the hierarchical likelihood approach. Hereafter, we use the term $h$-likelihood for short, which is more commonly seen in the literature [72,73]. Also, it provides a new way of statistical inferences in entire fields of statistical science. Recently, $h$-Likelihood is also commonly used for inferences and the application in big data and machine learning [74]. Therefore, we address likelihood for fitting SEMs that support various combinations of different distributions for response variables. In DHGLMs [72,74-76], the $h$-likelihood can be defined by the logarithm of the joint density of the response $y$ and the unobserved vectors of random effects $v, p$, and $q$ given by

$$
\begin{gathered}
h=h(\beta, \gamma, \delta, v, p, q ; y) \\
h=\log f_{\beta, \gamma, \delta}(y \mid v, p, q)+\log f_{\delta}(v \mid q)+\log f_{\alpha}(p)+\log f_{\tilde{\zeta}}(q)
\end{gathered}
$$

For estimation, we use $h$ for $v, p_{v}(h)$ for $\beta, p_{v, \beta}(h)$ for $(\gamma, \delta, p, q), p_{b, \beta, \gamma, p}(h)$ for $\alpha$ and $p_{v, \beta, \delta, q}(h)$ for $\xi$.

Author Contributions: Conceptualization, R.E.C., M.N., R.-C.C., and Y.L; methodology, R.E.C., M.N., and Y.L; software, R.E.C., M.N., and Y.L; validation, R.E.C., M.N., and Y.L.; formal analysis, R.E.C.; 
investigation, R.E.C.; resources, R.E.C., M.N., and Y.L., and data curation, R.E.C.; writing-original draft preparation, R.E.C., M.N., R.-C.C., and Y.L.; writing-review and editing, R.E.C., M.N., R.-C.C., Y.L., and P.U.G.; visualization, R.E.C., M.N., and P.U.G.; supervision, M.N., R.-C.C., Y.L., and B.P.; project administration, M.N., R.-C.C., Y.L., and B.P.; funding acquisition, M.N., R.-C.C., Y.L., and B.P. All authors have read and agreed to the published version of the manuscript.

Funding: This research is supported by National Research Foundation of Korea grants [NRF2019R1A2C1002408]. This research is part of Ministry of Science and Technology, Taiwan [MOST109-2622-E-324-004]. This research is part of Chaoyang University of Technology and the Higher Education Sprout Project, Ministry of Education (MOE), Taiwan, under the project name: “The R\&D and the cultivation of talent for health-enhancement products". This research is supported by Faculty of Economics and Business, Universitas Indonesia.

Data Availability Statement: Further information about the data and conditions for access are available at the Environmental Protection Administration of Taiwan. The analysis codes used in this paper available from the corresponding author upon reasonable request. Also, reader can reach Albatross Analytics website http:/ / cheoling.snu.ac.kr:3838/DHGLM/ (accessed on 24 December 2020) and STATCAL to perform graphical and statistical analysis.

Conflicts of Interest: The authors declare no conflict of interest.

\section{Appendix A}

Measurement model estimation approach by iteration procedure, where iteration will stop when it has reached a convergent condition. The iteration procedure in the HSEM algorithm is as follows:

- $\quad$ Step 0: Outer Weight Initialization. At this stage, an initialization is made, which is to determine any arbitrary value for outer weight. To make it easier, the weights of all indicators are the same: $w_{j k}$. Indicators are scaled to have unit variance (mean $=0$, variance $=1$ ).

- Step 1: Outside Approximation. After the outer weight is estimated, the estimation of the measurement model is then performed, which illustrates that the latent variable is the sum of the multiplication of weights with indicators.

- Step 2: Determination of Inner Weight. The initial value of the latent variable has been obtained; then, recalculate the latent variable differently. The latent variable is considered a linear combination of other related latent variables.

- Step 3: Structural Model Estimation (Inside Approximation). After the inner weight is obtained, then estimation is made of the structural model.

- $\quad$ Step 4: Updating the Weight of the Measurement Model or Updating Outer Weight. The process of updating the weight of the measurement model is divided into two; first, for reflective indicators (mode A) and, second, formative (mode B).

If the direction of the indicator used is reflective, then, using a simple linear regression, the latent variable in step 3 as a predictor and the indicator as a response. Where the method used is the least square method by minimizing the number of $e_{j k}$ error squares as mode A: 


$$
\begin{gathered}
e_{j k}=x_{j k}-w_{j k} z_{j k} \\
\sum_{j=1}^{J} e_{j k}^{2}=\sum_{j=1}^{J}\left(x_{j k}-w_{j k} z_{j}\right)^{2} \\
\frac{\partial \sum_{j=1}^{J} e_{j k}^{2}}{\partial w_{j k}}=2 \sum_{j=1}^{J}\left(x_{j k}-w_{j k} z_{j}\right)\left(z_{j}\right)=0 \\
\sum_{j=1}^{J}\left(x_{j k}-w_{j k} z_{j}\right)-\left(z_{j}\right)=0 \\
\sum_{j=1}^{J} x_{j k} z_{j}-\sum_{j=1}^{J} w_{j k} z_{j}^{2}=0 \\
\sum_{j=1}^{J} x_{j k} z_{j}-w_{j k} \sum_{j=1}^{J} z_{j}^{2}=0 \\
\sum_{j=1}^{J} x_{j k} z_{j}=w_{j k} \sum_{j=1}^{J} z_{j}^{2} ; w_{j k}=\frac{\sum_{j=1}^{J} x_{j k} z_{j}}{\sum_{j=1}^{J} z_{j}^{2}} \\
\hat{w}_{j k}=E\left(\frac{\sum_{j=1}^{J} x_{j k} z_{j}}{\sum_{j=1}^{J} z_{j}^{2}}\right)=\frac{\operatorname{Cov}\left(x_{j k} z_{j}\right)}{\operatorname{Var}\left(z_{j}^{2}\right)}=\left(z_{j}^{T} z_{j}\right)^{T} z_{j}^{T} x_{j k}
\end{gathered}
$$

In mode $\mathrm{B}$, the vector $w_{j}$ from the $w_{j k}$ weighting is a vector of multiple regression coefficients of $z_{j}$ on the $x_{j k}$ indicator that is connected to latent variable $\xi_{j}$. Then, $x_{j}$ is a matrix with columns defined by the $x_{j k}$ indicator connecting $j$ latent, and $z_{j}$ is a matrix containing $j$ latent variable data. Steps 1 to 4 are repeated until the conditions converge. If, in each iteration, there is $S=1,2,3, \ldots$ until to converge, the determination of convergence can be done by: if the outer weight on iteration to $S$ minus the outer weight on iteration to $S-1$ is less than $10^{-5}$.

$$
\begin{aligned}
& z_{j}=w_{j} x_{j}+\varepsilon_{j} \\
& \varepsilon_{j}=z_{j}-w_{j} x_{j}
\end{aligned}
$$

Solving the $\varepsilon_{j}^{T} \varepsilon_{j}$ :

$$
\begin{gathered}
\varepsilon_{j}^{T} \varepsilon_{j}=\left(z_{j}-w_{j} x_{j}\right)^{T}\left(z_{j}-w_{j} x_{j}\right) \\
\varepsilon_{j}^{T} \varepsilon_{j}=\left(z_{j}^{T}-w_{j}^{T} x_{j}^{T}\right)\left(z_{j}-w_{j} x_{j}\right) \\
\varepsilon_{j}^{T} \varepsilon_{j}=z_{j}^{T} z_{j}-2 w_{j} x_{j}^{T}+w_{j}^{T} w_{j} x_{j}^{T} x_{j} \\
\frac{\partial \varepsilon_{j}^{T} \varepsilon_{j}}{\partial w_{j}}=0-2 x_{j}^{T} z_{j}^{T}+2 w_{j} x_{j}^{T} x_{j}=0 \\
-x_{j}^{T} z_{j}=w_{j} x_{j}^{T} x_{j}=0 \\
x_{j}^{T} z_{j}=w_{j} x_{j}^{T} x_{j} \\
w_{j}=\frac{x_{j}^{T} z_{j}}{x_{j}^{T} x_{j}}=\left(x_{j}^{T} x_{j}\right)^{-1} x_{j}^{T} z_{j}
\end{gathered}
$$

\section{References}

1. Fletcher, R.; Rammelt, C. Decoupling: A Key Fantasy of the Post-2015 Sustainable Development Agenda. Globalizations 2017, 14, 450-467. [CrossRef]

2. World Health Organization. Health in 2015: From MDGs, Millennium Development Goals to SDGs, Sustainable Development Goals; World Health Organization: Geneva, Switzerland, 2015.

3. Lim, S.S.; Allen, K.; Bhutta, Z.A.; Dandona, L.; Forouzanfar, M.H.; Fullman, N.; Gething, P.W.; Goldberg, E.M.; Hay, S.I.; Holmberg, M.; et al. Measuring the health-related Sustainable Development Goals in 188 countries: A baseline analysis from the Global Burden of Disease Study 2015. Lancet 2016, 388, 1813-1850. [CrossRef]

4. Nilsson, M.; McCollum, D.; Echeverri, L.G.; Riahi, K.; Parkinson, S. A Guide to SDG Interactions: From Science to Implementation; International Council for Science: Paris, France, 2017.

5. Opoku, A. SDG2030: A sustainable built environment's role in achieving the post-2015 United Nations sustainable development goals. In Proceedings of the 32nd Annual ARCOM Conference, Manchester, UK, 5-7 September 2016.

6. Akseer, N.; Lawn, J.E.; Keenan, W.; Konstantopoulos, A.; Cooper, P.; Ismail, Z.; Thacker, N.; Cabral, S.; Bhutta, Z.A. Ending preventable newborn deaths in a generation. Int. J. Gynecol. Obstet. 2015, 131, S43-S48. [CrossRef] 
7. Joint United Nations Programme on HIV/AIDS, UNAIDS 2017. Ending Aids Progress Towards the 90-90-90 Targets. Glob Aids Updat 2017. Available online: https:/ / www.unaids.org/sites/default/files/media_asset/Global_AIDS_update_2017_en.pdf (accessed on 24 December 2020).

8. Suthar, A.B.; Zachariah, R.; Harries, A.D. Ending tuberculosis by 2030: Can we do it? Int. J. Tuberc. Lung Dis. 2016, 20, 1148-1154. [CrossRef]

9. Fitzpatrick, C.; Nwankwo, U.; Lenk, E.; de Vlas, S.J.; Bundy, D.A.P. An Investment Case for Ending Neglected Tropical Diseases. In Disease Control Priorities, 3rd ed.; Major Infectious Diseases; Woldbank Group: Washington, DC, USA, 2017 ; Volume 6.

10. Radhakrishnan, S.K.; Layden, T.J.; Gartel, A.L. RNA interference as a new strategy against viral hepatitis. Virology 2004, 323, 173-181. [CrossRef] [PubMed]

11. Caraka, R.E.; Yasin, H. Geographically Weighted Regression (GWR) Sebuah Pendekatan Regresi Geografis, 1st ed.; Mobius Graha Ilmu: Yogyakarta, Indonesia, 2017; Available online: www.rezzyekocaraka.com/book (accessed on 24 December 2020).

12. Wetli, C. Pathology of Drug Abuse. In Drug Abuse Handbook, 2nd ed.; CRC Press: London, UK, 2006.

13. Caraka, R.E.; Chen, R.C.; Yasin, H.; Pardamean, B.; Toharudin, T.; Wu, S.H. Prediction of Status Particulate Matter 2.5 using State Markov Chain Stochastic Process and HYBRID VAR-NN-PSO. IEEE Access 2019, 7, 161654-161665. [CrossRef]

14. Akimoto, H. Global Air Quality and Pollution. Science 2003, 302, 1716-1719. [CrossRef] [PubMed]

15. Rossati, A. Global warming and its health impact. Int. J. Occup. Environ. Med. 2017, 8, 7. [CrossRef] [PubMed]

16. Hales, S.; Edwards, S.J.; Kovats, R.S. Impacts on health of climate extremes. Clim. Chang. Hum. Health Risks Responses 2003, 5 , 79-102.

17. Searle, K.; Gow, K. Do concerns about climate change lead to distress? Int. J. Clim. Chang. Strateg. Manag. 2010, 2, 362-379. [CrossRef]

18. Tuangratananon, T.; Wangmo, S.; Widanapathirana, N.; Pongutta, S.; Viriyathorn, S.; Patcharanarumol, W.; Thin, K.; Nagpal, S.; Nuevo, C.E.L.; Padmawati, R.S.; et al. Implementation of national action plans on noncommunicable diseases, Bhutan, Cambodia, Indonesia, Philippines, Sri Lanka, Thailand and Vietnam. Bull. World Health Organ. 2019, 97, 129. [CrossRef]

19. Caraka, R.E.; Lee, Y.; Kurniawan, R.; Herliansyah, R.; Kaban, P.A.; Nasution, B.I.; Gio, P.U.; Chen, R.C.; Toharudin, T.; Pardamean, B. Impact of COVID-19 large scale restriction on environment and economy in Indonesia. Glob. J. Environ. Sci. Manag. 2020, 6, 65-84.

20. Lanckriet, G.; Cristianini, N. Learning the kernel matrix with semidefinite programming. J. Mach. Learn. Res. 2004, 5, 27-72. Available online: http:/ / dl.acm.org/ citation.cfm?id=1005334 (accessed on 24 December 2020).

21. Capriotti, T. HIV/AIDS: An update for home healthcare clinicians. Home Healthc. Now 2018, 36, 348-355. [CrossRef]

22. Snyder, J.E. Trend analysis of medical publications about LGBT persons: 1950-2007. J. Homosex. 2011, 2, 164-188. [CrossRef] [PubMed]

23. Wilkinson, R.G. The epidemiological transition: From material scarcity to social disadvantage? Daedalus 1994, 123, 61-77.

24. Chan, E.Y.Y.; Hung, H. Key Public Health Challenges for Health-EDRM in the Twenty-First Century: Demographic and Epidemiological Transitions. In Public Health and Disasters; Springer: Singapore, 2020; pp. 19-38.

25. Li, L.; Zhang, Q.; Wang, X.; Zhang, J.; Wang, T.; Gao, T.L.; Duan, W.; Tsoi, K.K.F.; Wang, F.Y. Characterizing the Propagation of Situational Information in Social Media during COVID-19 Epidemic: A Case Study on Weibo. IEEE Trans. Comput. Soc. Syst. 2020, 7, 556-562. [CrossRef]

26. Allen, L.N.; Nicholson, B.D.; Yeung, B.Y.T.; Goiana-da-Silva, F. Implementation of non-communicable disease policies: A geopolitical analysis of 151 countries. Lancet Glob. Health 2020, 8, e50-e58. [CrossRef]

27. McDonald, K.; Maurer, B.J. Familial aortic valve disease: Evidence for a genetic influence? Eur. Heart J. 1989, 10, 676-677. [CrossRef] [PubMed]

28. American Diabetes Association. Diagnosis and classification of diabetes mellitus. Diabetes Care 2009, 32 (Suppl. 1), S62-S67. [CrossRef]

29. Dreyer, M. Type 1 diabetes. Diabetologe 2019. [CrossRef]

30. Chen, R.C.; Caraka, R.E.; Arnita, N.E.G.; Pomalingo, S.; Rachman, A.; Toharudin, T.; Tai, S.K.; Pardamean, B. An End to End of Scalable Tree Boosting System. Sylwan 2020, 165, 1-11.

31. Nugroho, N.T.; Herten, M.; Osada, N.; Sielker, S.; Torsello, G.B. Correlation Among Six Single Nucleotide Polymorphisms Related to Cell Survival, Inflammation and Lipoprotein Regulation for Abdominal Aortic Aneurysm Risk Factor. J. Vasc. Surg. 2018, 67, e232-e233. [CrossRef]

32. Caraka, R.E.; Nugroho, N.T.; Tai, S.-K.; Chen, R.C.; Toharudin, T.; Pardamean, B. Feature Importance of The Aortic Anatomy on Endovascular Aneurysm Repair (EVAR) using Boruta and Bayesian MCMC. Commun. Math. Biol. Neurosci. 2020, 2020, 1-23.

33. Lederle, F.A. The Aneurysm Detection and Management Study Screening Program. Arch. Intern. Med. 2000, 160, 1425-1430. [CrossRef]

34. Virdis, A.; Giannarelli, C.; Fritsch Neves, M.; Taddei, S.; Ghiadoni, L. Cigarette Smoking and Hypertension. Curr. Pharm. Des. 2010, 16, 2518-2525. [CrossRef]

35. Budiarto, A.; Febriana, T.; Suparyanto, T.; Caraka, R.E.; Pardamean, B. Health Assistant Wearable-Based Data Science System Model: A Pilot Study. In Proceedings of the 2018 International Conference Information Management Technology (ICIMTech), Jakarta, Indonesia, 3-5 September 2018; pp. 438-442. 
36. Zhang, M.; Li, J.; Sun, H. The Experience and Enlightenment of the Reform and Development of Higher Engineering Education in Taiwan. In Proceedings of the 3rd International Conference on Education, Economics and Management Research 2019, Singapore, 29-30 November 2019; pp. 349-351.

37. Kao, C.; Pao, H.L. An evaluation of research performance in management of 168 Taiwan universities. Scientometrics 2009, 78, 261-277. [CrossRef]

38. Hou, A.Y.C.; Hill, C.; Hu, Z.; Lin, L. What is driving Taiwan government for policy change in higher education after the year of 2016-in search of egalitarianism or pursuit of academic excellence? Stud. High Educ. 2020. [CrossRef]

39. Yu, T.-K.; Lavallee, J.P.; Giusto BDi Chang, I.-C.; Yu, T.-Y. Risk perception and response toward climate change for higher education students in Taiwan. Environ. Sci. Pollut. Res. 2020, 27, 24749-24759. [CrossRef] [PubMed]

40. Sudiana, K.; Sule, E.T.; Soemaryani, I.; Yunizar, Y. The development and validation of the Penta Helix construct. Bus. Theory Pract. 2020, 21, 136-145. [CrossRef]

41. Dong, R.; Li, L.; Zhang, Q.; Cai, G. Information Diffusion on Social Media during Natural Disasters. IEEE Trans. Comput. Soc. Syst. 2018, 5, 265-276. [CrossRef]

42. De Carvalho, P.P.S.; De Araújo Kalid, R.; Rodríguez, J.L.M. Evaluation of the city logistics performance through structural equations model. IEEE Access 2019, 7, 121081-121094. [CrossRef]

43. Yusra, Y.; Agus, A. Online Food Delivery Service Quality: Does Personal Innovativeness Matter? Asia Proc. Soc. Sci. 2018, 2, 251-255. [CrossRef]

44. Yusra, Y.; Agus, A. The influence of perceived service quality towards customer satisfaction and Loyalty in Airasia self check-in system. J. Soc. Sci. Res. 2018, 766-775. [CrossRef]

45. Yusra, Y.; Agus, A. The influence of online food delivery service quality on customer satisfaction and customer loyalty: The role of personal innovativeness. J. Environ. Treat. Tech. 2020, 8, 6-12.

46. Irfan, M.; Hassan, M.; Hassan, N. The effect of project management capabilities on project success in Pakistan: An empirical investigation. IEEE Access 2019, 7, 39417-39431. [CrossRef]

47. Kurniawan, R.; Siagian, T.H.; Yuniarto, B.; Nasution, B.I.; Caraka, R.E. Construction of social vulnerability index in Indonesia using partial least squares structural equation modeling. Int. J. Eng. Technol. 2018, 7, 6131-6136.

48. Binsawad, M.H. Corporate Social Responsibility in Higher Education: A PLS-SEM Neural Network Approach. IEEE Access 2020, 8, 29125-29131. [CrossRef]

49. Gio, P.U.; Caraka, R.E. Membuat Berbagai Grafik Dengan Statcal-Visualization; Qiara Media: Provinsi Jawa Timur, Indonesia, 2020; ISBN 9786237925590.

50. Sutiksno, D.U.; Gio, P.U.; Caraka, R.E.; Ahmar, A.S. Brief Overview of STATCAL Statistical Application Program. J. Phys. Conf. Ser. 2018, 1028, 012244. [CrossRef]

51. Lee, Y.; Rönnegård, L.; Noh, M. Data Analysis Using Hierarchical Generalized Linear Models with R, 1st ed.Chapman and Hall/CRC: London, UK, 2017; Available online: https:/ / doi.org/10.1201/9781315211060 (accessed on 24 December 2020).

52. Jin, S.; Noh, M.; Lee, Y. H-Likelihood Approach to Factor Analysis for Ordinal Data. Struct. Equ. Model. Multidiscip. J. 2018, 25, 530-540. [CrossRef]

53. Jin, S.; Noh, M.; Yang-Wallentin, F.; Lee, Y. Robust nonlinear structural equation modeling with interaction between exogenous and endogenous latent variables. Struct. Equ. Model. Multidiscip. J. 2021. [CrossRef]

54. Jin, S. Essays on Estimation Methods for Factor Models and Structural Equation Models. Digital Comprehensive Summaries of Uppsala Dissertations from the Faculty of Social Sciences. Ph.D. Thesis, University of Uppsala, Uppsala, Swenden, 2015.

55. Ketchen, D.J. A Primer on Partial Least Squares Structural Equation Modeling; Sage Publications: London, UK, 2013.

56. Tenenhaus, M. Component-based structural equation modelling. Total Qual. Manag. 2008, 19, 871-886. [CrossRef]

57. Noh, M.; Lee, Y.; Oud, J.H.L.; Toharudin, T. Hierarchical likelihood approach to non-Gaussian factor analysis. J. Stat. Comput. Simul. 2019, 89, 1555-1573. [CrossRef]

58. Hui, F.K.C.; Warton, D.I.; Ormerod, J.T.; Haapaniemi, V.; Taskinen, S. Variational Approximations for Generalized Linear Latent Variable Models. J. Comput. Graph. Stat. 2017, 26, 35-43. [CrossRef]

59. Leguina, A. A primer on partial least squares structural equation modeling (PLS-SEM). Int. J. Res. Method Educ. 2015, 38, 220-221. [CrossRef]

60. Agustina, R.; Dartanto, T.; Sitompul, R.; Susiloretni, K.A.; Achadi, E.L.; Taher, A.; Wirawan, F.; Sungkar, S.; Sudarmono, P.; Shankar, A.H.; et al. Universal health coverage in Indonesia: Concept, progress, and challenges. Lancet 2019, 393, 75-102. [CrossRef]

61. Dartanto, T.; Rezki, J.F.; Pramono, W.; Siregar, C.H.; Bintara, U.; Bintara, H. Participation of Informal Sector Workers in Indonesia's National Health Insurance System. J. Southeast Asian Econ. 2016, 33, 317-342.

62. Martini, L.; Tjakraatmadja, J.H.; Anggoro, Y.; Pritasari, A.; Hutapea, L. Triple Helix Collaboration to Develop Economic Corridors as Knowledge Hub in Indonesia. Procedia Soc. Behav. Sci. 2012, 52, 130-139. [CrossRef]

63. Gaillard, S.; Roche, L.; Deschênes, G.; Morin, D.; Vianey-Saban, C.; Acquaviva-Bourdain, C.; Nony, P.; Subtil, F.; Mercier, C.; Cochat, P.; et al. Collaboration between academics, small pharmaceutical company and patient organizations in the development of a new formulation of cysteamine in nephropathic cystinosis: A successful story. Therapies 2020, 75, 169-173. [CrossRef]

64. Hagglund, K.J.; Deuser, W.E.; Buckelew, S.P.; Hewett, J.; Kay, D.R. Weather, beliefs about weather, and disease severity among patients with fibromyalgia. Arthritis Rheum. 1994, 7, 130-135. [CrossRef] 
65. Jackson, M.L.; Hart, G.R.; McCulloch, D.J.; Adler, A.; Brandstetter, E.; Fay, K.; Han, P.; Lacombe, K.; Lee, J.; Sibley, T.; et al. Effects of weather-related social distancing on city-scale transmission of respiratory viruses. medRxiv 2020, 5. [CrossRef]

66. Nawaz, Z. Emerging Infectious Diseases and Flu, Coronavirus and Allergy. Emerg. Infect. Dis. Diagn. 2020, 2, 1-4.

67. Hsih, W.H.; Cheng, M.Y.; Ho, M.W.; Chou, C.H.; Lin, P.C.; Chi, C.Y.; Liao, W.C.; Chen, C.Y.; Leong, L.Y.; Tien, N.; et al. Featuring COVID-19 cases via screening symptomatic patients with epidemiologic link during flu season in a medical center of central Taiwan. J. Microbiol. Immunol. Infect. 2020, 53, 459-466. [CrossRef] [PubMed]

68. Skrondal, A.; Rabe-Hesketh, S. Some Applications of Generalized Linear Latent and Mixed Models in Epidemiology. Nor. Epidemiol. 2003, 13, 265-278.

69. Herliansyah, R.; Fitria, I. Latent variable models for multi-species counts modeling in ecology. Biodivers. J. Biol. Divers. 2018, 19, 1871-1876. [CrossRef]

70. Caraka, R.E.; Shohaimi, S.; Kurniawan, I.D.; Herliansyah, R.; Budiarto, A.; Sari, S.P.; Pardamean, B. Ecological Show Cave and Wild Cave: Negative Binomial Gllvm's Arthropod Community Modelling. Procedia Comput. Sci. 2018, 135, 377-384. [CrossRef]

71. Niku, J.; Hui, F.K.C.; Taskinen, S.; Warton, D.I. gllvm: Fast analysis of multivariate abundance data with generalized linear latent variable models in r. Methods Ecol. Evol. 2019, 10, 2173-2182. [CrossRef]

72. Lee, Y.; Nelder, J.A. Hierarchical Generalized Linear Models. J. R. Stat. Soc. Ser. B 1996, 58, 619-656. [CrossRef]

73. Jin, S.; Lee, Y. A review of h-likelihood and hierarchical generalized linear model. Wiley Interdiscip. Rev. Comput. Stat. 2020, e1527. [CrossRef]

74. Caraka, R.E.; Lee, Y.; Chen, R.C.; Toharudin, T. Using Hierarchical Likelihood Towards Support Vector Machine: Theory and Its Application. IEEE Access 2020, 8, 194795-194807. [CrossRef]

75. Lee, Y.; Noh, M. Package 'dhglm'. Appl. Stat. 2015, 55, 139-185.

76. Noh, M.; Ok, Y.J.; Na, M.H.; Ng, C.T. Analysis of degradation data using double hierarchical generalized linear model. Korean Data Inf. Sci. Soc. 2018, 29, 217-228. 